\title{
Association of diet and lifestyle with blood pressure in the Guangxi Hei Yi Zhuang and Han populations
}

\author{
Yin Ruixing ${ }^{1, *}$, Li Hui ${ }^{2}$, Wu Jinzhen ${ }^{1}$, Lin Weixiong ${ }^{3}$, Yang Dezhai $^{3}$, Pan Shangling ${ }^{4}$, \\ Huang Jiandong ${ }^{5}$ and Long Xiuyan ${ }^{5}$ \\ 'Department of Cardiology, Institute of Cardiovascular Diseases, The First Affiliated Hospital, Guangxi Medical \\ University, 22 Shuangyong Road, Nanning 530021, Guangxi, People's Republic of China: ${ }^{2}$ Clinical Laboratory \\ of the Affiliated Cancer Hospital, Guangxi Medical University, Nanning, People's Republic of China: \\ ${ }^{3}$ Department of Molecular Biology, Guangxi Medical Scientific Research Center, Nanning, People's Republic of \\ China: ${ }^{4}$ Department of Pathophysiology, School of Premedical Sciences, Guangxi Medical University, Nanning, \\ People's Republic of China: ${ }^{5}$ The Health Bureau of Napo County, Guangxi Zhuang Autonomous Region, Napo, \\ Guangxi, People's Republic of China
}

\section{Submitted 24 August 2007: Accepted 3 April 2008: First published online 19 May 2008}

\begin{abstract}
Objective: To detect the association of diet and lifestyle with blood pressure in the Guangxi Hei Yi Zhuang and Han populations.

Design: A cross-sectional study of hypertension.

Setting: Both populations were from seven to nine villages in Napo County, Guangxi Zhuang Autonomous Region, China.

Subjects: A total of 1068 subjects of Hei Yi Zhuang and 933 participants of Han Chinese aged 20-89 years were surveyed by a stratified randomised cluster sampling.

Results: The levels of systolic blood pressure and pulse pressure were higher in Hei Yi Zhuang than in Han (125.20 (SD 18.62) v. 121.88 (SD 15.99) $\mathrm{mmHg}$ and 48.64 (sD 14.75) v. 44.98 (sD 11.12) mmHg, $P<0.001$ for each, respectively). The prevalence of hypertension and isolated systolic hypertension was also higher in Hei Yi Zhuang than in Han $(25 \cdot 19 \% v .17 \cdot 26 \%$ and $12 \cdot 45 \% v .3 \cdot 86 \%, P<0 \cdot 001$ for each, respectively). Mean arterial pressure was positively correlated with gender, age, physical activity, TAG, alcohol consumption, cigarette smoking, total energy, total fat and salt intakes, and negatively associated with education level and total dietary fibre intake in Hei Yi Zhuang $(P<0 \cdot 05-0 \cdot 001)$, whereas it was positively associated with gender, age, physical activity, BMI, waist circumference, total cholesterol, alcohol consumption, cigarette smoking, total energy, total fat and salt intakes, and negatively associated with education level and total dietary fibre intake in Han $(P<0 \cdot 05-0 \cdot 001)$.

Conclusions: The differences in blood pressure levels and the prevalence of hypertension between the Hei Yi Zhuang and Han populations were associated with different dietary habits, lifestyle choices, education level, as well as geographical surroundings.
\end{abstract}

Keywords
Blood pressure
Hypertension
Prevalence
Diet
Lifestyle
Hypertension is a principal cause of mortality and morbidity in China ${ }^{(1)}$, and is also one of the most important cardiovascular risk factors all over the world ${ }^{(2)}$. A recent cross-sectional study in China estimated that 129 million people aged 35-74 years have hypertension ${ }^{(3)}$. Although the exact causes and mechanisms of hypertension are not well known, it is generally believed that genetic factors $^{(4)}$ as well as environmental factors, such as more sodium intake ${ }^{(5,6)}$, cigarette smoking ${ }^{(7,8)}$ and mental work $^{(9,10)}$, are involved in determining blood pressure levels and the prevalence of hypertension. In addition, the prevalence of hypertension in different races may also differ ${ }^{(11,12)}$.

There are fifty-six ethnic groups in China. Han is the largest ethnic group and Zhuang is the largest minority. There are also forty-three ethnic subgroups of the Zhuang. Hei Yi Zhuang dwelling in Napo County (a county near Vietnam) of Guangxi is an isolated subgroup. They worship black colour, and they like to wear black garments and pants. Black colour has become the marking of Hei Yi Zhuang. The population size is 51655 . Because of isolation from the other ethnic groups, the special customs 
and cultures including their clothing, intra-ethnic marriages, dietary habits and lifestyle are still totally conserved to the present day ${ }^{(13)}$. Little is known about the association of diet and lifestyle with blood pressure in this population. We hypothesise that there may be significant differences in the dietary patterns, lifestyle and blood pressure levels between the two ethnic groups. Therefore, the present study was undertaken to detect the association of diet and lifestyle with blood pressure and the prevalence of hypertension in the Guangxi Hei Yi Zhuang and Han populations.

\section{Methods}

\section{Populations}

A total of 1068 subjects of Hei Yi Zhuang from seven villages in Napo County, Guangxi Zhuang Autonomous Region, China, were surveyed by a stratified randomised cluster sampling. The ages of the subjects ranged from 20 to 84 years, with an average age of $46 \cdot 75$ (SD $15 \cdot 66$ ) years. There were $487(45 \cdot 6 \%)$ males and 581 (54.4\%) females. All of them were peasants. The numbers of subjects between the ages of 20-29, 30-39, 40-49, 50-59, 60-69 and $\geq 70$ years were $156(14 \cdot 6 \%), 255(23.8 \%), 177$ (16.6\%), $196(18 \cdot 4 \%), 196(18 \cdot 4 \%)$ and $88(8 \cdot 2 \%)$, respectively. They accounted for $2 \cdot 1 \%$ of the total Hei Yi Zhuang population. During the same period, a total of 933 subjects of Han Chinese from nine villages in the same county were also surveyed by the same method. The mean age of the subjects was $45 \cdot 46$ (SD 15.76) years (range 20-89 years). There were $414(44 \cdot 4 \%)$ men and 519 (55.6\%) women. These subjects were also peasants. The numbers of subjects between the ages of 20-29, 30-39, 40-49, 50-59, 60-69 and $\geq 70$ years were 183 (19.6\%), $230(24 \cdot 7 \%), 173(18 \cdot 5 \%), 149$ (16.0\%), 117 $(12 \cdot 5 \%)$ and $81(8 \cdot 7 \%)$, respectively. All study subjects were essentially healthy and had no evidence of any chronic illness, including hepatic, renal, thyroid, cardiac dysfunction or diabetes mellitus. Some subjects were treated with antihypertensive drugs, such as nifedipine (calcium channel blocker) and/or catopril (angiotensin converting enzyme inhibitor). The study was approved by our institutional ethics committee, and the study subjects gave informed consent to participate in the study.

\section{Epidemiological survey}

The survey was carried out using internationally standardised methods ${ }^{(14)}$, following a common protocol. Information on demographics (age, gender, race/ethnicity and residential area), socio-economic status (education level achieved, marital status and annual household income), health-related behaviour (alcohol consumption, cigarette smoking and physical activity) and dietary intake was collected with standardised questionnaires. Dietary information of each subject was obtained using a $24 \mathrm{~h}$ dietary recall method ${ }^{(15)}$. Detailed descriptions of all foods, beverages and supplements consumed during the $24 \mathrm{~h}$ period before the interview, including the quantity, cooking method and brand names, were recorded by a chief physician. Quantitative estimate of cumulative nutrient intake per day in each food was based on food tables derived from the 2002 Chinese Food Composition Tables ${ }^{(16)}$. Overall physical activity was ascertained with the use of a modified version of the Harvard Alumni Physical Activity Questionnaire ${ }^{(17)}$, which included questions about the number of hours per day (mean of a regular weekday and a regular weekend day) spent sleeping and in sedentary, light, moderate and vigorous activities; the interviewer ensured that the total time added up to $24 \mathrm{~h}$. Current smoking was defined as more than one cigarette per day. Consumption of alcohol included questions about the number of liangs (about $50 \mathrm{~g}$ ) of rice wine, wine, beer or liquor consumed during the preceding 12 months. The physical examination included blood pressure, height, weight and waist circumference. Blood pressure readings were taken with a standard mercury sphygmomanometer after at least 5 min of rest, while the subject was in a sitting position. The values used in the current analysis are means of three measurements taken by the same investigator at about 5 min intervals. Systolic blood pressure (SBP) was determined by the first Korotkoff sound, and diastolic blood pressure (DBP) by the fifth Korotkoff sound. Pulse pressure (PP) was calculated as the difference between SBP and DBP. Mean arterial pressure (MAP) was calculated as DBP plus one-third times $\mathrm{PP}^{(18)}$. Body weight (to the nearest $100 \mathrm{~g}$ on calibrated scales) and height (to the nearest $0.5 \mathrm{~cm}$ ) were measured while the participants were wearing only light indoor clothing and no shoes. BMI was calculated as weight ( $\mathrm{kg}$ ) divided by height $(\mathrm{m})$ squared. Waist circumference was measured with a nonstretchable measuring tape, at the level of the smallest area of the waist, to the nearest $0 \cdot 1 \mathrm{~cm}$.

\section{Measurements of lipids and apolipoproteins}

Blood samples were drawn from an antecubital vein in all subjects after an overnight fast. The blood was transferred into glass tubes and allowed to clot at room temperature. Immediately following clotting, serum was separated by centrifugation for $15 \mathrm{~min}$ at $3000 \mathrm{rpm}$. The levels of total cholesterol, TAG, HDL cholesterol (HDL-C) and LDL cholesterol (LDL-C) in samples were determined enzymatically using commercially available kits: Tcho-1, TGLH (RANDOX Laboratories Ltd, Crumlin, UK), Cholestest N HDL and Cholestest LDL (Daiichi Pure Chemicals Co., Ltd, Tokyo, Japan), respectively. Serum apo A1 and apo B levels were measured by an immunoturbidimetric assay (RANDOX Laboratories Ltd). All determinations were performed with an autoanalyser (Type 7170A; Hitachi Ltd, Tokyo, Japan) in the Clinical Science Experiment Center of the First Affiliated Hospital, Guangxi Medical University. 


\section{Diagnostic criteria}

Hypertension was defined as an average SBP of $140 \mathrm{mmHg}$ or greater and/or an average DBP of $90 \mathrm{mmHg}$ or greater $^{(19)}$, and/or self-reported pharmacological treatment for hypertension within the 2 weeks prior to the interview. The subjects with only $\mathrm{SBP} \geq 140 \mathrm{mmHg}$ and $\mathrm{DBP}<90 \mathrm{mmHg}$ were defined as isolated systolic hypertension. Awareness of hypertension was defined as a self-report of any prior diagnosis of hypertension by a health-care professional. Treatment of hypertension was defined as a self-reported use of pharmacological medication for the management of high blood pressure within the 2 weeks preceding the participant's interview. Control of hypertension was defined as having an average SBP $<140 \mathrm{mmHg}$ and an average DBP $<90 \mathrm{mmHg}$ in the context of pharmacological treatment of hypertension. The normal values of serum total cholesterol, TAG, HDL-C, LDL-C, apo A1, apo B and the ratio of apo A1 to apo B in our Clinical Science Experiment Center were 3·10-5·17, $0 \cdot 56-1 \cdot 70,0 \cdot 91-1 \cdot 81,1 \cdot 70-3 \cdot 20 \mathrm{mmol} / 1,1 \cdot 00-1 \cdot 76,0 \cdot 63$ $1 \cdot 14 \mathrm{~g} / \mathrm{l}$ and $1 \cdot 00-2 \cdot 50$, respectively. Normal weight, overweight and obesity were defined as a BMI $<24,24-28$ and $>28 \mathrm{~kg} / \mathrm{m}^{2}$, respectively ${ }^{(20)}$.

\section{Statistical analysis}

The data were organised and analysed using EXCEL XP (Microsoft, Seattle, WA, USA) and SPSS for Windows version 11.5 (SPSS Inc., Chicago, IL, USA). Means and standard deviations (SD) as well as frequency distributions of participant characteristics were calculated. The difference of two parameters between Hei Yi Zhuang and Han was tested by Student's unpaired $t$-test. One-way ANOVA was performed to assess the differences of three and more parameters. Significant difference was then subjected to multiple comparison using the NewmanKeuls test. The difference of percentage was tested by the $\chi^{2}$ tests. In order to evaluate the association between the MAP and ethnic group (Han =0; Hei Yi Zhuang=1), gender (female $=0$; male $=1$ ), age (year), education level (years), physical activity (h/week), BMI $\left(\mathrm{kg} / \mathrm{m}^{2}=1\right)$, waist circumference $(\mathrm{cm})$, total cholesterol $(\mathrm{mmol} / \mathrm{l})$, TAG (mmol/l), LDL-C (mmol/l), apo B (g/l), alcohol consumption (non-drinkers $=0 ;<25 \mathrm{~g} / \mathrm{d}=1 ; 25-49 \mathrm{~g} / \mathrm{d}=2$; 50-99g/d=3; $\geq 100 \mathrm{~g} / \mathrm{d}=4$ ), cigarette smoking (nonsmokers $=0 ;<10$ cigarettes $/ \mathrm{d}=1 ; 10-19$ cigarettes $/ \mathrm{d}=2$; 20-39 cigarettes $/ \mathrm{d}=3 ; \geq 40$ cigarettes $/ \mathrm{d}=4$ ) and the intakes of total energy $(\mathrm{kJ} / \mathrm{d})$, total fat $(\mathrm{g} / \mathrm{d})$, dietary cholesterol $(\mathrm{mg} / \mathrm{d})$, total dietary fibre $(\mathrm{g} / \mathrm{d})$ and salt intake $(\mathrm{g} / \mathrm{d})$, unconditional logistic regression analysis were also performed in combined population of Hei Yi Zhuang and Han, Hei Yi Zhuang, and Han, respectively. The backward multiple logistic regression method was used to select the risk factors significantly associated with MAP. The total intake of each nutrient was summed over all foods consumed. Matlab5.0 software was used for the quantitative estimate of cumulative nutrient intake per day ${ }^{(21)}$. A $P$ value of $<0.05$ was considered significant.

\section{Results}

\section{General characteristics between Hei Yi Zhuang and Han}

The demographic characteristics, dietary intake and other lifestyle factors between Hei Yi Zhuang and Han are shown in Table 1. The intakes of carbohydrate, total dietary fibre and salt, mean residential altitude, and the percentages of subjects who consumed alcohol in Hei Yi Zhuang were higher than those in Han $(P<0 \cdot 05-0 \cdot 001)$, whereas the education level, body weight, BMI, waist circumference, and the intakes of total energy, total fat, protein and dietary cholesterol in Han were higher than those in Hei Yi Zhuang $(P<0 \cdot 001$ for all). There were no differences in physical activity level, body height, the percentages of subjects who smoked cigarettes and sex distribution between the two ethnic groups $(P>0 \cdot 05)$.

\section{Blood pressure levels and prevalence of bypertension}

As shown in Table 1, the levels of SBP and PP in Hei Yi Zhuang were higher than those in $\operatorname{Han}(P<0 \cdot 001$ for each), but there was no difference in DBP levels between Hei Yi Zhuang and Han $(P>0 \cdot 05)$. The crude prevalence rates of hypertension and isolated systolic hypertension were also higher in Hei Yi Zhuang than in Han $(25 \cdot 19 \%$ v. 17.26\% and $12 \cdot 45 \% v \cdot 3 \cdot 86 \%, P<0 \cdot 001$ for each, respectively).

\section{Awareness, treatment and control of bypertension}

Of the 269 subjects with hypertension in Hei Yi Zhuang, $8.55 \%$ were aware of their high blood pressure, $4.46 \%$ were treated and $1.86 \%$ were controlled, whereas the rates of awareness, treatment and control in Han were $21 \cdot 12 \%(P<0 \cdot 001), 15.53 \%(P<0 \cdot 001)$ and $10.56 \%$ $(P<0 \cdot 001)$, respectively (Table 1$)$.

\section{Association of demographic and lifestyle factors witb blood pressure}

The association of sex, age, BMI, alcohol consumption and cigarette smoking with blood pressure levels between Hei Yi Zhuang and Han is shown in Table 2. SBP, DBP and MAP in both Hei Yi Zhuang and Han were higher in men than in women $(P<0.001$ for all $)$, but there was no significant difference in PP between both sexes. SBP, DBP, PP and MAP increased progressively with age in both ethnic groups $(P<0 \cdot 01-0 \cdot 001)$. SBP levels in both ethnic groups were higher in drinkers than in non-drinkers $(P<0 \cdot 01$ for each). The levels of DBP and MAP in both ethnic groups were higher in drinkers than in non-drinkers, or in smokers than in non-smokers $(P<0 \cdot 001$ for all). In addition, the levels of DBP and MAP in Han were higher in drinkers than in non-drinkers $(P<0 \cdot 01)$. 
Table 1 General characteristics and blood pressure levels between the Hei Yi Zhuang and Han populations

\begin{tabular}{|c|c|c|c|c|c|c|}
\hline \multirow[b]{2}{*}{ Characteristic } & \multicolumn{2}{|c|}{ Hei Yi Zhuang ( $n$ 1068) } & \multicolumn{2}{|c|}{ Han Chinese ( $n$ 933) } & \multirow[b]{2}{*}{$t\left(\chi^{2}\right)$} & \multirow[b]{2}{*}{$P$} \\
\hline & Mean or $n$ & SD or $\%$ & Mean or $n$ & SD or $\%$ & & \\
\hline Age (years) & $46 \cdot 75$ & $15 \cdot 66$ & $45 \cdot 46$ & $15 \cdot 76$ & $1 \cdot 833$ & 0.067 \\
\hline Male/female & \multicolumn{2}{|c|}{$487 / 581$} & \multicolumn{2}{|c|}{$414 / 519$} & 0.303 & 0.582 \\
\hline Education level (years) & $2 \cdot 85$ & 0.95 & 3.98 & $1 \cdot 72$ & $18 \cdot 484$ & 0.000 \\
\hline Physical activity (h/week) & $39 \cdot 48$ & $13 \cdot 22$ & $38 \cdot 76$ & $13 \cdot 45$ & $1 \cdot 206$ & $0 \cdot 228$ \\
\hline Residential altitude $(\mathrm{m})$ & $9479 \cdot 85$ & $87 \cdot 18$ & $814 \cdot 65$ & $121 \cdot 27$ & $30 \cdot 166$ & 0.000 \\
\hline Height (cm) & $153 \cdot 18$ & $7 \cdot 96$ & $152 \cdot 66$ & $8 \cdot 17$ & $1 \cdot 440$ & $0 \cdot 150$ \\
\hline Weight (kg) & $49 \cdot 98$ & $7 \cdot 37$ & $52 \cdot 42$ & $7 \cdot 99$ & $7 \cdot 103$ & 0.000 \\
\hline BMI $\left(\mathrm{kg} / \mathrm{m}^{2}\right)$ & $21 \cdot 25$ & $2 \cdot 27$ & $22 \cdot 43$ & $2 \cdot 50$ & $11 \cdot 064$ & 0.000 \\
\hline$>24 \mathrm{~kg} / \mathrm{m}^{2} \ddagger$ & 123 & $11 \cdot 52$ & 202 & $21 \cdot 65$ & $37 \cdot 591$ & 0.000 \\
\hline Waist circumference $(\mathrm{cm})$ & $73 \cdot 73$ & $6 \cdot 84$ & $74 \cdot 86$ & $7 \cdot 75$ & $3 \cdot 465$ & 0.001 \\
\hline Alcohol consumption $\ddagger$ & 592 & $55 \cdot 43$ & 466 & $49 \cdot 95$ & $6 \cdot 011$ & 0.014 \\
\hline Cigarette smoking $\ddagger$ & 332 & $31 \cdot 09$ & 266 & $28 \cdot 51$ & $1 \cdot 577$ & 0.209 \\
\hline Energy (kJ/d) & $8755 \cdot 48$ & $278 \cdot 52$ & $8890 \cdot 72$ & $325 \cdot 75$ & $10 \cdot 011$ & 0.000 \\
\hline Carbohydrate (g/d) & $366 \cdot 12$ & $25 \cdot 76$ & $292 \cdot 11$ & $21 \cdot 25$ & $69 \cdot 498$ & 0.000 \\
\hline Protein $(\mathrm{g} / \mathrm{d})$ & $52 \cdot 30$ & $5 \cdot 78$ & $79 \cdot 67$ & $7 \cdot 87$ & $89 \cdot 377$ & 0.000 \\
\hline Total fat $(\mathrm{g} / \mathrm{d})$ & $39 \cdot 52$ & $5 \cdot 67$ & $61 \cdot 38$ & $6 \cdot 85$ & $78 \cdot 076$ & 0.000 \\
\hline Dietary cholesterol $(\mathrm{mg} / \mathrm{d})$ & $176 \cdot 33$ & $105 \cdot 47$ & $195 \cdot 67$ & $116 \cdot 25$ & $3 \cdot 901$ & 0.000 \\
\hline Total dietary fibre $(\mathrm{g} / \mathrm{d})$ & $8 \cdot 87$ & $3 \cdot 44$ & $6 \cdot 72$ & $2 \cdot 54$ & $15 \cdot 712$ & 0.000 \\
\hline Salt intake (g/d) & $8 \cdot 76$ & $3 \cdot 75$ & $7 \cdot 58$ & $2 \cdot 64$ & $8 \cdot 092$ & 0.000 \\
\hline $\mathrm{SBP}(\mathrm{mmHg})$ & $125 \cdot 20$ & $18 \cdot 62$ & $121 \cdot 88$ & $15 \cdot 99$ & $4 \cdot 247$ & 0.000 \\
\hline DBP $(\mathrm{mmHg})$ & $76 \cdot 56$ & $11 \cdot 06$ & $76 \cdot 95$ & $10 \cdot 03$ & $0 \cdot 822$ & 0.411 \\
\hline $\mathrm{PP}(\mathrm{mmHg})$ & $48 \cdot 64$ & $14 \cdot 75$ & $44 \cdot 98$ & $11 \cdot 12$ & $6 \cdot 196$ & 0.000 \\
\hline Isolated SBP $\geq 140 \mathrm{mmHg} \ddagger$ & 133 & $12 \cdot 45$ & 36 & $3 \cdot 86$ & $47 \cdot 571$ & 0.000 \\
\hline Isolated $\mathrm{DBP} \geq 90 \mathrm{mmHg}$ & 35 & $3 \cdot 28$ & 42 & $4 \cdot 50$ & $2 \cdot 018$ & $0 \cdot 155$ \\
\hline Both $\mathrm{SBP} \geq 140$ and $\mathrm{DBP} \geq 90 \mathrm{mmHg} \ddagger$ & 101 & $9 \cdot 46$ & 83 & $8 \cdot 90$ & $0 \cdot 188$ & 0.664 \\
\hline Hypertension prevalenceł & 269 & $25 \cdot 19$ & 161 & $17 \cdot 26$ & $18 \cdot 566$ & 0.000 \\
\hline Awareness rateł & 23 & $8 \cdot 55$ & 34 & $21 \cdot 12$ & $13 \cdot 835$ & 0.000 \\
\hline Treatment rateł & 12 & $4 \cdot 46$ & 25 & $15 \cdot 53$ & $15 \cdot 686$ & 0.000 \\
\hline Control rate $\ddagger$ & 5 & $1 \cdot 86$ & 17 & $10 \cdot 56$ & $15 \cdot 705$ & 0.000 \\
\hline
\end{tabular}

SBP, systolic blood pressure; DBP, diastolic blood pressure; PP, pulse pressure.

Data are presented as means and standard deviations or łas numbers of subjects and percentages.

\section{Association of demographic and lifestyle factors with the prevalence of bypertension}

The association of demographic and lifestyle factors with the prevalence of hypertension is shown in Table 3. The prevalence of hypertension in both ethnic groups was higher in males than in females, or in smokers than in non-smokers $(P<0.01$ for all). In addition, the prevalence of hypertension in Han was higher in drinkers than in non-drinkers $(P<0 \cdot 01)$.

\section{Correlative factors for mean arterial pressure}

Table 4 gives the results of multivariate logistic regression analysis. MAP was positively correlated with Hei Yi Zhuang, male, age, physical activity, BMI, waist circumference, total cholesterol, TAG, alcohol consumption, cigarette smoking, and total energy, total fat and salt intakes, and negatively associated with education level and total dietary fibre intake in a combined population of Hei Yi Zhuang and Han $(P<0 \cdot 05-0 \cdot 001)$. MAP was positively correlated with male, age, physical activity, TAG, alcohol consumption, cigarette smoking, and total energy, total fat and salt intakes, and negatively associated with education level and total dietary fibre intake in Hei Yi Zhuang $(P<0 \cdot 05-0 \cdot 001)$, whereas it was positively associated with male, age, physical activity, BMI, waist circumference, total cholesterol, alcohol consumption, cigarette smoking, and total energy, total fat and salt intakes, and negatively associated with education level and total dietary fibre intake in Han $(P<0 \cdot 05-0 \cdot 001)$. No association was observed between MAP and LDL-C, apo B or dietary cholesterol intake $(P>0 \cdot 05)$.

\section{Discussion}

In the present study, we show that SBP and PP levels are higher in Hei Yi Zhuang than in Han. The prevalence of hypertension and isolated systolic hypertension is also higher in Hei Yi Zhuang than in Han. The disparity in blood pressure and the prevalence of hypertension between the two ethnic groups is multifactorial. The vast majority of Hei Yi Zhuang people reside in the mountainous areas. The mean residential altitude is higher than that in Han. It has been found that as the altitude increases gradually, the reference value of whole blood contrast viscosity also increases gradually, and the correlation is quite obvious ${ }^{(22,23)}$. A recent study has shown that chronic hypoxia causes marked activation of the sympathetic nervous system in healthy humans and increased SBP, despite normalisation of the arterial $\mathrm{O}_{2}$ content with acclimatisation ${ }^{(24)}$. Increased secretion of 
Table 2 Association of demographic characteristics and lifestyle factors with blood pressure levels between the Hei Yi Zhuang and Han populations

\begin{tabular}{|c|c|c|c|c|c|c|c|c|c|}
\hline \multirow[b]{2}{*}{ Variable } & \multirow[b]{2}{*}{$n$} & \multicolumn{2}{|c|}{$\mathrm{SBP}(\mathrm{mmHg})$} & \multicolumn{2}{|c|}{$\mathrm{DBP}(\mathrm{mmHg})$} & \multicolumn{2}{|c|}{$\mathrm{PP}(\mathrm{mmHg})$} & \multicolumn{2}{|c|}{ MAP $(\mathrm{mmHg})$} \\
\hline & & Mean & SD & Mean & SD & Mean & SD & Mean & SD \\
\hline \multicolumn{10}{|l|}{ Hei Yi Zhuang } \\
\hline Male & 487 & $127 \cdot 57$ & 18.99 & $78 \cdot 58$ & $11 \cdot 45$ & $49 \cdot 01$ & $14 \cdot 81$ & 94.92 & $13 \cdot 13$ \\
\hline Female & 581 & $120 \cdot 93^{\star \star \star}$ & $17 \cdot 77$ & $73 \cdot 51^{\star \star *}$ & $10 \cdot 38$ & $47 \cdot 44$ & $14 \cdot 26$ & $89 \cdot 32^{\star \star \star}$ & $2 \cdot 32$ \\
\hline $\mathrm{BMI} \leq 24 \mathrm{~kg} / \mathrm{m}^{2}$ & 945 & $125 \cdot 34$ & $18 \cdot 84$ & $76 \cdot 49$ & 11.06 & $48 \cdot 86$ & 14.97 & $92 \cdot 78$ & 13.02 \\
\hline $\mathrm{BMI}>24 \mathrm{~kg} / \mathrm{m}^{2}$ & 123 & $124 \cdot 07$ & $16 \cdot 80$ & $77 \cdot 11$ & $11 \cdot 15$ & 46.95 & $12 \cdot 99$ & $92 \cdot 76$ & $12 \cdot 07$ \\
\hline Non-drinker & 476 & $123 \cdot 47$ & $19 \cdot 11$ & $74 \cdot 44$ & $10 \cdot 64$ & $49 \cdot 03$ & $15 \cdot 45$ & $90 \cdot 78$ & $13 \cdot 05$ \\
\hline Drinker & 592 & $126 \cdot 59^{\star *}$ & $18 \cdot 11$ & $78 \cdot 27^{\star \star \star}$ & $11 \cdot 11$ & $48 \cdot 33$ & $14 \cdot 18$ & $94 \cdot 38^{\star \star \star}$ & 12.65 \\
\hline Non-smoker & 736 & $124 \cdot 08$ & $18 \cdot 61$ & $75 \cdot 29$ & $10 \cdot 88$ & $48 \cdot 79$ & $14 \cdot 82$ & $91 \cdot 55$ & $12 \cdot 85$ \\
\hline Smoker & 332 & $126 \cdot 35$ & $17 \cdot 90$ & $79 \cdot 01^{\star \star \star}$ & $10 \cdot 91$ & $47 \cdot 34$ & $14 \cdot 84$ & $94 \cdot 79^{\star \star \star}$ & $12 \cdot 88$ \\
\hline \multicolumn{10}{|l|}{ Age (years) } \\
\hline $20-29$ & 156 & $118 \cdot 74$ & $13 \cdot 21$ & $74 \cdot 21$ & $10 \cdot 38$ & $44 \cdot 57$ & $10 \cdot 84$ & $89 \cdot 07$ & $10 \cdot 61$ \\
\hline $30-39$ & 255 & $119 \cdot 27$ & $14 \cdot 49$ & $75 \cdot 31$ & $9 \cdot 44$ & 43.96 & 11.03 & 89.96 & $10 \cdot 24$ \\
\hline $40-49$ & 177 & $120 \cdot 96$ & $13 \cdot 46$ & $77 \cdot 72$ & $10 \cdot 36$ & $43 \cdot 30$ & $10 \cdot 00$ & $92 \cdot 15$ & $10 \cdot 18$ \\
\hline $50-59$ & 196 & $127 \cdot 19$ & $18 \cdot 89$ & $77 \cdot 81$ & $11 \cdot 37$ & $49 \cdot 39$ & $14 \cdot 16$ & $94 \cdot 27$ & $12 \cdot 77$ \\
\hline $60-69$ & 196 & $134 \cdot 87$ & $22 \cdot 78$ & $77 \cdot 75$ & $12 \cdot 69$ & $57 \cdot 12$ & $18 \cdot 12$ & $96 \cdot 79$ & $15 \cdot 41$ \\
\hline$\geq 70$ & 88 & $136 \cdot 22$ & $21 \cdot 11$ & $76 \cdot 42$ & $12 \cdot 44$ & $59 \cdot 80$ & $16 \cdot 68$ & $96 \cdot 35$ & $14 \cdot 56$ \\
\hline$F$ for six age subgroups & - & \multirow{2}{*}{\multicolumn{2}{|c|}{$\begin{array}{r}31.979 \\
0.000\end{array}$}} & \multicolumn{2}{|c|}{3.450} & \multicolumn{2}{|c|}{$42 \cdot 012$} & \multicolumn{2}{|c|}{11.970} \\
\hline $\mathrm{P}$ for six age subgroups & - & & & 0.0 & & 0. & & & \\
\hline \multicolumn{10}{|l|}{ Han Chinese } \\
\hline Male & 414 & $124 \cdot 05 t+$ & $16 \cdot 06$ & $79 \cdot 51$ & $10 \cdot 44$ & $44 \cdot 63+t t$ & $11 \cdot 21$ & $94 \cdot 39$ & $10 \cdot 83$ \\
\hline Female & 519 & $120 \cdot 35^{\star \star \star}$ & $15 \cdot 77$ & $75 \cdot 16^{\star \star \star},+\dagger$ & $9 \cdot 33$ & $45 \cdot 22 t t$ & $11 \cdot 05$ & $90 \cdot 23^{\star \star \star}$ & $10 \cdot 19$ \\
\hline $\mathrm{BMI} \leq 24 \mathrm{~kg} / \mathrm{m}^{2}$ & 730 & $121 \cdot 34 t+t$ & $16 \cdot 10$ & $76 \cdot 34$ & $9 \cdot 70$ & $45 \cdot 02+t+$ & $11 \cdot 26$ & $91 \cdot 35$ & $10 \cdot 4 \varepsilon$ \\
\hline $\mathrm{BMI}>24 \mathrm{~kg} / \mathrm{m}^{2}$ & 203 & $123 \cdot 72$ & $15 \cdot 48$ & $79 \cdot 06^{\star \star \star}$ & $10 \cdot 88$ & $44 \cdot 83$ & $10 \cdot 64$ & $94 \cdot 01^{* *}$ & $10 \cdot 76$ \\
\hline Non-drinker & 467 & $120 \cdot 32 t+$ & $16 \cdot 08$ & $75 \cdot 75$ & $9 \cdot 51$ & $44 \cdot 63+t t$ & $11 \cdot 30$ & $90 \cdot 63$ & $10 \cdot 41$ \\
\hline Drinker & 466 & $123 \cdot 44^{\star \star}, \mathrm{t \dagger}$ & $15 \cdot 75$ & $78 \cdot 15^{\star \star \star}$ & $10 \cdot 40$ & $45 \cdot 32+t t$ & $10 \cdot 94$ & $93 \cdot 26^{\star \star \star}$ & $10 \cdot 67$ \\
\hline Non-smoker & 667 & $121 \cdot 20+t$ & $16 \cdot 10$ & $75 \cdot 96$ & $9 \cdot 70$ & $45 \cdot 26+t+$ & $11 \cdot 24$ & $91 \cdot 05$ & $10 \cdot 47$ \\
\hline Smoker & 266 & $123 \cdot 55^{\star}, t$ & $15 \cdot 60$ & $79 \cdot 40^{\star \star \star}$ & $10 \cdot 42$ & $44 \cdot 27+t+$ & $10 \cdot 80$ & $94 \cdot 16^{\star \star \star}$ & $10 \cdot 25$ \\
\hline \multicolumn{10}{|l|}{ Age (years) } \\
\hline $20-29$ & 183 & $115 \cdot 75 t$ & $11 \cdot 89$ & $74 \cdot 10$ & $8 \cdot 36$ & $41 \cdot 75+t$ & $8 \cdot 86$ & $88 \cdot 02$ & $8 \cdot 61$ \\
\hline $30-39$ & 230 & $117 \cdot 72$ & $12 \cdot 71$ & $75 \cdot 13$ & $8 \cdot 23$ & $42 \cdot 72$ & $9 \cdot 59$ & $89 \cdot 37$ & 8.91 \\
\hline $40-49$ & 173 & $120 \cdot 65$ & $14 \cdot 26$ & $77 \cdot 08$ & $9 \cdot 65$ & $43 \cdot 57$ & $9 \cdot 59$ & $91 \cdot 60$ & $9 \cdot 62$ \\
\hline $50-59$ & 149 & $125 \cdot 15$ & $16 \cdot 85$ & $79 \cdot 28$ & $10 \cdot 92$ & $45 \cdot 87 \dagger$ & $11 \cdot 54$ & 94.57 & $11 \cdot 23$ \\
\hline $60-69$ & 117 & $128 \cdot 13+t$ & $17 \cdot 74$ & 78.91 & $11 \cdot 27$ & $49 \cdot 22+t t$ & 11.48 & $95 \cdot 32$ & $11 \cdot 38$ \\
\hline$\geq 70$ & 81 & $134 \cdot 88$ & $19 \cdot 65$ & $81 \cdot 02$ & $12 \cdot 37$ & 53.85 & $14 \cdot 62$ & 98.97 & 13.50 \\
\hline$F$ for six age subgroups & - & \multicolumn{2}{|c|}{$27 \cdot 722$} & \multicolumn{2}{|c|}{$10 \cdot 122$} & \multicolumn{2}{|c|}{21.585} & \multicolumn{2}{|c|}{$20 \cdot 737$} \\
\hline$P$ for six age subgroups & - & \multicolumn{2}{|c|}{0.000} & \multicolumn{2}{|c|}{0.000} & \multicolumn{2}{|c|}{0.000} & \multicolumn{2}{|c|}{0.000} \\
\hline
\end{tabular}

SBP, systolic blood pressure; DBP, diastolic blood pressure; PP, pulse pressure; MAP, mean arterial pressure.

Mean values were significantly different from those of male, BMI $\leq 24 \mathrm{~kg} / \mathrm{m}^{2}$, non-drinker or non-smoker subgroups of the same ethnic group: ${ }^{\star} P<0 \cdot 05$, ${ }^{\star \star} P<0.01,{ }^{* \star \star} P<0.001$.

Mean values were significantly different from those of Hei Yi Zhuang: $+P<0.05,{ }_{t+} P<0.01,{ }_{t+t} P<0.001$.

catecholamine $^{(24,25)}$, vasopressin ${ }^{(26)}$ and adrenocorticotropin $^{(27)}$ may promote the development of hypertension by the renin-angiotensin-aldosterone system ${ }^{(28)}$.

Corn gruel or hoecake is the staple food throughout the year in Hei Yi Zhuang. There are three meals a day on an ordinary day, and four meals on a farming day. Salt is the main flavouring. The intake of salt is very high. Long-term high salt intake is an important risk factor for hypertension ${ }^{(5)}$. Several large randomised trials and meta-analyses of trials have shown that a reduction in salt intake lowers blood pressure in hypertensive individuals ${ }^{(6,29)}$.

The climate in Napo County is like the south subtropics. Evaporation is quick, and the weather is very dry and cold in winter at the mountain top. Cold exposure has been shown to be a risk factor for hypertension ${ }^{(30)}$. SBP and DBP were significantly higher in the coldexposed workers. In logistic regression analysis, cold exposure severity was a significant variable affecting hypertension in cold-exposed workers ${ }^{(30)}$.
Hei Yi Zhuang people reside in the infertile mountain area, which is $30 \%$ soil with $70 \%$ rock. The earnings derive mostly from planting corn and paddy. It is not easy for adolescents to go to junior high school. Thus, the education level is widespread lower, and the knowledge of necessary health care is very poor ${ }^{(11,31)}$.

The association of sex and age with blood pressure has been extensively studied. Currently, it is believed that the prevalence of hypertension is higher in males than in females, and both blood pressure and the prevalence of hypertension increase with age ${ }^{(32,33)}$. The present study also shows that SBP and DBP are higher in men than in women in both ethnic groups. SBP, DBP, PP and MAP in both ethnic groups are all increased progressively with age. MAP is also positively correlated with male gender and age in both populations. This may relate to the overwork and unwholesome lifestyle in $\operatorname{men}^{(34)}$. Job stress has been shown in prospective studies to have adverse effects on the development of hypertension and 
Table 3 Association of demographic characteristics and lifestyle factors with the prevalence of hypertension between the Hei Yi Zhuang and Han populations

\begin{tabular}{|c|c|c|c|c|c|c|c|c|c|}
\hline \multirow[b]{2}{*}{ Variable } & \multirow[b]{2}{*}{$n$} & \multicolumn{2}{|c|}{$\mathrm{SBP} \geq 140 \mathrm{mmHg}$} & \multicolumn{2}{|c|}{$\mathrm{DBP} \geq 90 \mathrm{mmHg}$} & \multicolumn{2}{|c|}{$\mathrm{SBP} \geq 140$ and $\mathrm{DBP} \geq 90 \mathrm{mmHg}$} & \multicolumn{2}{|c|}{ Prevalence of hypertension } \\
\hline & & $n$ & $\%$ & $n$ & $\%$ & $n$ & $\%$ & $n$ & $\%$ \\
\hline \multicolumn{10}{|l|}{ Hei Yi Zhuang } \\
\hline Male & 487 & 66 & $13 \cdot 6$ & 28 & $5 \cdot 7$ & 70 & $14 \cdot 4$ & 164 & $33 \cdot 7$ \\
\hline Female & 581 & 67 & $11 \cdot 5$ & $7^{\star \star \star}$ & $1 \cdot 2$ & $31^{\star \star \star}$ & $5 \cdot 3$ & $105^{\star \star \star}$ & $18 \cdot 1$ \\
\hline $\mathrm{BMI} \leq 24 \mathrm{~kg} / \mathrm{m}^{2}$ & 945 & 124 & $13 \cdot 1$ & 29 & $3 \cdot 1$ & 87 & $9 \cdot 2$ & 240 & $25 \cdot 4$ \\
\hline $\mathrm{BMI}>24 \mathrm{~kg} / \mathrm{m}^{2}$ & 123 & 9 & $7 \cdot 3$ & 6 & 4.9 & 14 & $11 \cdot 4$ & 29 & $23 \cdot 6$ \\
\hline Non-drinker & 476 & 63 & $13 \cdot 2$ & 11 & $2 \cdot 3$ & 33 & 6.9 & 107 & $22 \cdot 5$ \\
\hline Drinker & 592 & 70 & $11 \cdot 8$ & 24 & $4 \cdot 1$ & $68^{*}$ & $11 \cdot 5$ & 162 & $27 \cdot 4$ \\
\hline Non-smoker & 736 & 88 & $12 \cdot 0$ & 17 & $2 \cdot 3$ & 62 & $8 \cdot 4$ & 167 & $22 \cdot 7$ \\
\hline Smoker & 332 & 45 & $13 \cdot 6$ & $18^{\star *}$ & $5 \cdot 4$ & 39 & $11 \cdot 7$ & $102^{\star \star}$ & $30 \cdot 7$ \\
\hline \multicolumn{10}{|l|}{ Age (years) } \\
\hline $20-29$ & 156 & 8 & $5 \cdot 1$ & 8 & $5 \cdot 1$ & 2 & $1 \cdot 3$ & 18 & $11 \cdot 5$ \\
\hline $30-39$ & 255 & 15 & $5 \cdot 9$ & 7 & $2 \cdot 7$ & 13 & $5 \cdot 1$ & 35 & $13 \cdot 7$ \\
\hline $40-49$ & 177 & 8 & $4 \cdot 5$ & 10 & $5 \cdot 6$ & 17 & $9 \cdot 6$ & 35 & $19 \cdot 8$ \\
\hline $50-59$ & 196 & 30 & $15 \cdot 3$ & 6 & $3 \cdot 1$ & 20 & $10 \cdot 2$ & 56 & $28 \cdot 6$ \\
\hline $60-69$ & 196 & 50 & $25 \cdot 5$ & 4 & $2 \cdot 0$ & 34 & $17 \cdot 3$ & 88 & $44 \cdot 9$ \\
\hline$\geq 70$ & 88 & 22 & $25 \cdot 0$ & 0 & & 15 & $17 \cdot 1$ & 37 & $42 \cdot 1$ \\
\hline$\chi^{2}$ for six age subgroups & - & \multicolumn{2}{|c|}{$72 \cdot 814$} & \multirow{2}{*}{\multicolumn{2}{|c|}{$9 \cdot 013$}} & \multirow{2}{*}{\multicolumn{2}{|c|}{$\begin{array}{r}38 \cdot 134 \\
0.000\end{array}$}} & \multicolumn{2}{|c|}{$90 \cdot 828$} \\
\hline$\hat{P}$ for six age subgroups & - & \multicolumn{2}{|c|}{0.000} & $0 \cdot 109$ & & & & \multicolumn{2}{|c|}{0.000} \\
\hline \multicolumn{10}{|l|}{ Han Chinese } \\
\hline Male & 414 & $15 t$ & $3 \cdot 6$ & 30 & $7 \cdot 2$ & 44 & $10 \cdot 6$ & $89 \mathrm{c}$ & $21 \cdot 5$ \\
\hline Female & 519 & $21+t+$ & $4 \cdot 0$ & $12^{\star \star *}$ & $2 \cdot 3$ & 39 & $7 \cdot 5$ & $72^{\star *}$ & $13 \cdot 9$ \\
\hline $\mathrm{BMI} \leq 24 \mathrm{~kg} / \mathrm{m}^{2}$ & 730 & $29+t+$ & $4 \cdot 0$ & 29 & $4 \cdot 0$ & 60 & $8 \cdot 2$ & $118+t+$ & $16 \cdot 2$ \\
\hline $\mathrm{BMI}>24 \mathrm{~kg} / \mathrm{m}^{2}$ & 203 & 7 & $3 \cdot 4$ & 13 & $6 \cdot 4$ & 23 & $11 \cdot 3$ & 43 & $21 \cdot 2$ \\
\hline Non-drinker & 467 & $16+t+$ & $3 \cdot 4$ & 14 & $3 \cdot 0$ & 34 & $7 \cdot 3$ & $64+t+$ & $13 \cdot 7$ \\
\hline Drinker & 466 & $20+t+t$ & $4 \cdot 3$ & $28^{\star}$ & $6 \cdot 0$ & 49 & $10 \cdot 5$ & $97^{\star \star}, \dagger$ & $20 \cdot 8$ \\
\hline Non-smoker & 667 & $24+t+$ & $3 \cdot 6$ & 18 & $2 \cdot 7$ & 57 & 8.5 & $99+t+$ & $14 \cdot 8$ \\
\hline Smoker & 266 & $12+t+$ & $4 \cdot 5$ & $24^{\star \star \star}$ & $9 \cdot 0$ & 26 & $9 \cdot 8$ & $62^{\star \star}, \dagger$ & $23 \cdot 3$ \\
\hline \multicolumn{10}{|l|}{ Age (years) } \\
\hline $20-29$ & 183 & 3 & $1 \cdot 6$ & 6 & $3 \cdot 3$ & 5 & $2 \cdot 7$ & 14 & $7 \cdot 7$ \\
\hline $30-39$ & 230 & 6 & $2 \cdot 6$ & 6 & $2 \cdot 6$ & 7 & $3 \cdot 0$ & 19 & $8 \cdot 3$ \\
\hline $40-49$ & 173 & 2 & $1 \cdot 2$ & 12 & $6 \cdot 9$ & 11 & $6 \cdot 4$ & 25 & $14 \cdot 5$ \\
\hline $50-59$ & 149 & $8+t$ & $5 \cdot 4$ & 8 & $5 \cdot 4$ & 20 & $13 \cdot 4$ & 36 & $24 \cdot 2$ \\
\hline $60-69$ & 117 & $6+t+$ & $5 \cdot 1$ & 8 & $6 \cdot 8$ & 19 & $16 \cdot 2$ & $33+t$ & $28 \cdot 2$ \\
\hline$\geq 70$ & 81 & $11+$ & $13 \cdot 6$ & 2 & $2 \cdot 5$ & $21 a$ & 25.9 & 34 & $42 \cdot 0$ \\
\hline$\chi^{2}$ for six age subgroups & - & \multicolumn{2}{|c|}{$28 \cdot 866$} & \multicolumn{2}{|c|}{$7 \cdot 464$} & \multirow{2}{*}{\multicolumn{2}{|c|}{$\begin{array}{r}60 \cdot 211 \\
0.000\end{array}$}} & \multirow{2}{*}{\multicolumn{2}{|c|}{$\begin{array}{r}75 \cdot 276 \\
0.000\end{array}$}} \\
\hline$P$ for six age subgroups & - & & & $0 \cdot 1$ & & & & & \\
\hline
\end{tabular}

SBP, systolic blood pressure; DBP, diastolic blood pressure.

Number of subjects was significantly different from those of male, BMI $\leq 24 \mathrm{~kg} / \mathrm{m}^{2}$, non-drinker or non-smoker subgroups of the same ethnic group: ${ }^{\star} P<0 \cdot 05$, ${ }^{* *} P<0.01,{ }^{* * \star} P<0.001$.

Number of subjects was significantly different from those of Hei Yi Zhuang: $+P<0 \cdot 05,++P<0 \cdot 01,+t+P<0 \cdot 001$.

coronary artery disease, particularly in $\operatorname{men}^{(9)}$. SBP and DBP during the working day were greater in high job demand participants who were stress reactive than in other groups ${ }^{(10)}$.

Epidemiological studies have revealed that the prevalence of hypertension was 2- to 6-fold higher in obese than in normal weight populations ${ }^{(35,36)}$. An increase in BMI and a decrease in BMI were significantly associated with increased and decreased SBP and DBP, respectively ${ }^{(35)}$. In the present study, however, we fail to show an association of BMI and blood pressure in Hei Yi Zhuang. The reason for this discrepancy is unclear. In this study, the subjects with a BMI $>24 \mathrm{~kg} / \mathrm{m}^{2}$ were only $11.52 \%$ in Hei Yi Zhuang, suggesting that the association of BMI and blood pressure is weak in this population. In a recent investigation, $\mathrm{Biscevic}^{(36)}$ has shown that there was a higher correlation of blood pressure with waist circumference, than with BMI. In the present study, we also fail to show the association of MAP and waist circumference in Hei Yi Zhuang. However, our study shows that MAP was positively correlated with TAG in Hei Yi Zhuang, and was positively correlated with total cholesterol in $\operatorname{Han}^{(37)}$. The relationship between hypertension and hyperlipidaemia remains poorly understood. High blood pressure in patients with hyperlipidaemia may be a consequence of vascular endothelial dysfunction ${ }^{(34)}$.

Alcohol in larger amounts increases blood pressure and overall mortality ${ }^{(7,8,38)}$. The mechanisms involved in the pressor effect of a moderate dose of alcohol primarily reflects an increase in cardiac output and heart rate, possibly a consequence of increased sympathetic nerve activity ${ }^{(39)}$. Alcohol also alters cell membranes, allowing more calcium to enter, perhaps by inhibition of intracellular sodium transport ${ }^{(40)}$. In the present study, we also show that SBP, DBP and MAP levels in both ethnic groups were higher in drinkers than in non-drinkers. MAP was also positively correlated with alcohol consumption in both ethnic groups. These results suggest that alcohol 
Table 4 Correlative factors for mean arterial pressure between the Hei Yi Zhuang and Han populations

\begin{tabular}{|c|c|c|c|c|c|}
\hline Ethnic groups/correlative factors & $\begin{array}{c}\text { Regression } \\
\text { coefficient (RC) }\end{array}$ & Standard error & Standardised RC & $t$ & $P$ \\
\hline \multicolumn{6}{|l|}{ Hei plus Han } \\
\hline Ethnic group & 0.016 & 0.002 & $0 \cdot 215$ & $4 \cdot 578$ & 0.000 \\
\hline Sex & $0 \cdot 211$ & 0.073 & $0 \cdot 127$ & $2 \cdot 764$ & 0.004 \\
\hline Age & 0.009 & 0.003 & $0 \cdot 174$ & $3 \cdot 774$ & 0.000 \\
\hline Education level & -0.148 & 0.054 & $-0 \cdot 121$ & -2.657 & 0.006 \\
\hline Physical activity & 0.013 & 0.003 & $0 \cdot 242$ & $5 \cdot 335$ & 0.000 \\
\hline BMI & 0.098 & 0.047 & 0.087 & $2 \cdot 342$ & 0.016 \\
\hline Waist circumference & 0.023 & 0.012 & 0.095 & $2 \cdot 225$ & 0.023 \\
\hline Total cholesterol & 0.099 & 0.034 & 0.079 & $2 \cdot 293$ & 0.017 \\
\hline TAG & 0.002 & 0.001 & $0 \cdot 113$ & $2 \cdot 258$ & 0.019 \\
\hline Alcohol consumption & 0.008 & 0.006 & $0 \cdot 237$ & $5 \cdot 556$ & 0.000 \\
\hline Cigarette smoking & 0.007 & 0.004 & 0.112 & $2 \cdot 138$ & 0.031 \\
\hline Total energy & 0.014 & 0.005 & $0 \cdot 155$ & $3 \cdot 345$ & 0.001 \\
\hline Total fat & 0.003 & 0.002 & $0 \cdot 214$ & $4 \cdot 841$ & 0.000 \\
\hline Total dietary fibre & -0.177 & 0.054 & -0.139 & $-3 \cdot 321$ & 0.001 \\
\hline Salt intake & 0.002 & 0.003 & $0 \cdot 188$ & $4 \cdot 162$ & 0.000 \\
\hline \multicolumn{6}{|l|}{ Hei Yi Zhuang } \\
\hline Sex & $0 \cdot 155$ & 0.052 & 0.086 & $2 \cdot 683$ & 0.006 \\
\hline Age & 0.013 & 0.003 & $0 \cdot 187$ & $6 \cdot 112$ & 0.000 \\
\hline Education level & $-0 \cdot 117$ & 0.005 & -0.193 & $-3 \cdot 413$ & 0.000 \\
\hline Physical activity & 0.015 & 0.005 & 0.144 & $4 \cdot 463$ & 0.000 \\
\hline TAG & 0.004 & 0.003 & 0.097 & $2 \cdot 912$ & 0.004 \\
\hline Alcohol consumption & 0.008 & 0.002 & $0 \cdot 163$ & $4 \cdot 893$ & 0.000 \\
\hline Cigarette smoking & 0.002 & 0.008 & $0 \cdot 114$ & $2 \cdot 385$ & 0.018 \\
\hline Total energy & 0.012 & 0.002 & $0 \cdot 163$ & $4 \cdot 822$ & 0.000 \\
\hline Total fat & 0.010 & 0.001 & $0 \cdot 195$ & $6 \cdot 125$ & 0.000 \\
\hline Total dietary fibre & -0.131 & 0.011 & $-0 \cdot 112$ & -3.335 & 0.001 \\
\hline Salt intake & 0.055 & 0.012 & 0.146 & $4 \cdot 831$ & 0.000 \\
\hline \multicolumn{6}{|l|}{ Han Chinese } \\
\hline Sex & 0.076 & 0.014 & $0 \cdot 183$ & $3 \cdot 231$ & 0.000 \\
\hline Age & 0.014 & 0.003 & 0.201 & $4 \cdot 324$ & 0.000 \\
\hline Education level & -0.014 & 0.005 & -0.118 & -2.946 & 0.002 \\
\hline Physical activity & 0.005 & 0.002 & $0 \cdot 166$ & $4 \cdot 013$ & 0.000 \\
\hline BMI & 0.008 & 0.003 & 0.185 & 4.095 & 0.000 \\
\hline Waist circumference & 0.036 & 0.012 & $0 \cdot 145$ & 3.513 & 0.000 \\
\hline Total cholesterol & 0.005 & 0.004 & 0.099 & $2 \cdot 113$ & 0.031 \\
\hline Alcohol consumption & 0.002 & 0.002 & $0 \cdot 183$ & $4 \cdot 612$ & 0.000 \\
\hline Cigarette smoking & 0.068 & 0.025 & 0.097 & $2 \cdot 287$ & 0.022 \\
\hline Total energy & 0.057 & 0.023 & $0 \cdot 121$ & $2 \cdot 883$ & 0.003 \\
\hline Total fat & 0.015 & 0.004 & $0 \cdot 215$ & $5 \cdot 176$ & 0.000 \\
\hline Total dietary fibre & -0.034 & 0.008 & -0.186 & -4.554 & 0.000 \\
\hline Salt intake & 0.007 & 0.003 & $0 \cdot 145$ & 2.736 & 0.005 \\
\hline
\end{tabular}

consumption is a main risk factor for hypertension in both populations. The effect of different kinds of wine on blood pressure is not well known. In this study, 90\% of the wine consumed by Hei Yi Zhuang was corn wine and rum, in which the alcohol content is lower. On the contrary, a great deal of the wine consumed by Han is rice wine, in which the alcohol content is higher.

Cigarette smoking is a well-established cardiovascular risk factor. Cigarette smoking raises blood pressure, probably through the nicotine-induced release of noradrenaline from adrenergic nerve endings. In addition, smoking causes an acute and marked reduction in radial artery compliance ${ }^{(41)}$. When smokers quit, a trivial rise in blood pressure may occur, probably reflecting a gain in weight ${ }^{(42)}$. Waist girth increased more in men who quit smoking than in other men. An increase in waist girth during follow-up strongly predicted incident hypertension $^{(43)}$. In our study, we show that DBP and MAP levels in both ethnic groups were higher in smokers than in non-smokers. MAP was also positively correlated with cigarette smoking in both ethnic groups, suggesting that cigarette smoking is another independent risk factor for hypertension in these populations.

The rates of awareness, treatment and control are important indices of hypertensive treatment and prognosis. The rates of awareness, treatment and control in our country were $44 \cdot 7 \%, 28 \cdot 2 \%$ and $8 \cdot 1 \%$, respectively, in subjects aged $35-74$ years in $2001^{(3,44)}$. The results of the present study show that the rates of awareness, treatment and control in Hei Yi Zhuang were significantly lower than those in Han, and were also significantly lower than those in the rural population of China. The reason for this status is likely multifactorial; however, a lack of public awareness and understanding of hypertension and its complications may contribute to the epidemic of uncontrolled hypertension in this population. Increasing public awareness of hypertension using public education and health provider strategies should be a high national health priority. 
In conclusion, hypertension is found to be highly prevalent in the Hei Yi Zhuang population, and the rates of awareness, treatment and control are relatively lower. These results underscore the urgent need for developing a high blood pressure education programme to coordinate the effort of detection, prevention and treatment of hypertension in the national minority area of China.

\section{Acknowledgements}

Conflict of interest: No conflicts.

Funding support: This study was supported by the National Natural Science Foundation of China (No. 30360038).

Author contributions: Y.R. conceived the study, participated in the design, carried out the epidemiological survey, collected the samples and drafted the manuscript; L.H. performed the statistical analyses and helped to draft the manuscript; W.J., L.W. and Y.D. carried out the epidemiological survey, collected the samples and measured the lipids; P.S., H.J. and L.X. carried out the epidemiological survey and collected the samples. All authors read and approved the final manuscript.

\section{References}

1. He J, Gu D, Wu X et al. (2005) Major causes of death among men and women in China. $N$ Engl J Med 353, 1124-1134.

2. Roccella EJ \& Bowler AE (1990) Hypertension as a risk factor. Cardiovasc Clin 20, 49-63.

3. Gu D, Reynolds K, Wu X et al. (2002) Prevalence, awareness, treatment, and control of hypertension in China. Hypertension 40, 920-927.

4. Kamide K, Kokubo Y, Yang J et al. (2005) Hypertension susceptibility genes on chromosome 2p24-p25 in a general Japanese population. J Hypertens 23, 955-960.

5. Ukoh VA, Ukoh GC, Okosun RE \& Azubike E (2004) Salt intake in first degree relations of hypertensive and normotensive Nigerians. East Afr Med J 81, 524-528.

6. He FJ, Markandu ND \& Mac Gregor GA (2005) Modest salt reduction lowers blood pressure in isolated systolic hypertension and combined hypertension. Hypertension 46, 66-70.

7. Arquizan C, Touze E, Moulin T, Woimant F, Ducrocq X \& Mas JL (2005) Blood pressure, smoking and oral contraceptive control after cryptogenic stroke in young adults in the PFO-ASA Study. Cerebrovasc Dis 20, 41-45.

8. Sorensen K, Kristensen KS, Bang LE, Svendsen TL, Wiinberg N, Buttenschon L \& Talleruphuus U (2004) Increased systolic ambulatory blood pressure and microalbuminuria in treated and non-treated hypertensive smokers. Blood Press 13, 362-368.

9. Pickering TG (2001) Mental stress as a causal factor in the development of hypertension and cardiovascular disease. Curr Hypertens Rep 3, 249-254.

10. Steptoe A \& Cropley M (2000) Persistent high job demands and reactivity to mental stress predict future ambulatory blood pressure. J Hypertens 18, 581-586.

11. Ordunez P, Munoz JL, Espinosa-Brito A, Silva LC \& Cooper RS (2005) Ethnicity, education, and blood pressure in Cuba. Am J Epidemiol 162, 49-56.
12. Rehman SU, Hutchison FN, Hendrix K, Okonofua EC \& Egan BM (2005) Ethnic differences in blood pressure control among men at Veterans Affairs clinics and other health care sites. Arch Intern Med 165, 1041-1047.

13. Li RS, Yin RX, Lin WX \& Yang DZ (2005) Relationship between the polymorphism of microsomal triglyceride transfer protein gene and the level of serum lipids in Guangxi Heiyi Zhuang population. Zhonghua Yi Xue Za Zhi (Natl Med J China) 85, 2492-2496.

14. People's Republic of China-United States Cardiovascular and Cardiopulmonary Epidemiology Research Group (1992) An epidemiological study of cardiovascular and cardiopulmonary disease risk factors in four populations in the People's Republic of China. Baseline report from the PRC-USA Collaborative Study. Circulation 85, 1083-1096.

15. Lyu LC, Yeh CY, Lichtenstein AH, Li Z, Ordovas JM \& Schaefer EJ (2001) Association of sex, adiposity, and diet with HDL subclasses in middle-aged Chinese. Am J Clin Nutr 74, 64-71.

16. Yang YX, Wang GY \& Pan XC (2002) The 2002 Chinese Food Composition Table. Beijing: Medical Publishing House of Beijing University.

17. Paffenbarger RS, Wing AL \& Hyde RT (1978) Physical activity as an index of heart attack risk in college alumni. Am J Epidemiol 108, 161-175.

18. Zheng L, Sun Z, Li J et al. (2007) Mean arterial pressure: a better marker of stroke in patients with uncontrolled hypertension in rural areas of China. Intern Med $\mathbf{4 6}$, $1495-1500$.

19. Hansson L, Hedner T \& Himmelmann A (1999) The 1999 WHO-ISH Guidelines for the Management of Hypertension - new targets, new treatment and a comprehensive approach to total cardiovascular risk reduction. Blood Press Suppl 1, 3-5.

20. Cooperative Meta-analysis Group of China Obesity Task Force (2002) Predictive values of body mass index and waist circumference to risk factors of related diseases in Chinese adult population. Chin J Epidemiol 23, 5-10.

21. von Kamp A \& Schuster S (2006) Metatool 5.0: fast and flexible elementary modes analysis. Bioinformatics 22, 1930-1931.

22. Pei SX, Zhu SM, Li EL, Sui XL \& Gou JX (1989) Hemorrheological investigation on healthy natives and immigrants at $3658 \mathrm{~m}$ above sea level in Lhasa. Chin Med J (Engl) 102, 392-394.

23. Palareti G, Coccheri S, Poggi M, Tricarico MG, Magelli M \& Cavazzuti F (1984) Changes in the rheologic properties of blood after a high altitude expedition. Angiology 35, 451-458.

24. Calbet JA (2003) Chronic hypoxia increases blood pressure and noradrenaline spillover in healthy humans. J Physiol 551, 379-386.

25. Ohkuwa T, Itoh H, Yamamoto T, Minami C \& Yamazaki Y (2005) Effect of hypoxia on norepinephrine of various tissues in rats. Wilderness Environ Med 16, 22-26.

26. Maresh CM, Kraemer WJ, Judelson DA, VanHeest JL, Trad L, Kulikowich JM, Goetz KL, Cymerman A \& Hamilton AJ (2004) Effects of high altitude and water deprivation on arginine vasopressin release in men. Am J Physiol Endocrinol Metab 286, E20-E24.

27. Raff H, Shinsako J, Keil LC \& Dallman MF (1983) Vasopressin, ACTH, and blood pressure during hypoxia induced at different rates. Am J Physiol 245, E489-E493.

28. Porto PI, Garcia SI, Dieuzeide G, Gonzalez C \& Pirola CJ (2003) Renin-angiotensin-aldosterone system loci and multilocus interactions in young-onset essential hypertension. Clin Exp Hypertens 25, 117-130.

29. Whelton PK, Appel LJ, Espeland MA et al. (1998) Sodium reduction and weight loss in the treatment of hypertension 
in older persons: a randomized controlled trial of nonpharmacologic interventions in the elderly (TONE). TONE Collaborative Research Group. JAMA 279, 839-846.

30. Kim JY, Jung KY, Hong YS, Kim JI, Jang TW \& Kim JM (2003) The relationship between cold exposure and hypertension. J Occup Health 45, 300-306.

31. Oliveria SA, Chen RS, McCarthy BD, Davis CC \& Hill MN (2005) Hypertension knowledge, awareness, and attitudes in a hypertensive population. I Gen Intern Med $\mathbf{2 0}$, 219-225.

32. Carroll D, Ring C, Hunt K, Ford G \& Macintyre S (2003) Blood pressure reactions to stress and the prediction of future blood pressure: effects of sex, age, and socioeconomic position. Psychosom Med 65, 1058-1064.

33. Takizawa H, Ura N, Saitoh S et al. (2001) Gender difference in the relationships among hyperleptinemia, hyperinsulinemia, and hypertension. Clin Exp Hypertens 23, 357-368.

34. Xu XL, Tang XH \& Jin HY (2004) Relationship between blood pressure and blood lipids, glucose, weight in the population of three districts of Zhejiang province. Chin J Cardiovasc Med 9, 117-120.

35. Droyvold WB, Midthjell K, Nilsen TI \& Holmen J (2005) Change in body mass index and its impact on blood pressure: a prospective population study. Int J Obes Relat Metab Disord 29, 650-655.

36. Biscevic A (2005) Prehypertension, hypertension and obesity types. Med Arb 59, 94-96.

37. Tran TM, Komatsu T, Nguyen TK, Nguyen VC, Yoshimura Y, Takahashi K, Wariishi M, Sakai T \& Yamamoto S (2001) Blood pressure, serum cholesterol concentration and their related factors in urban and rural elderly of Ho Chi Minh City. J Nutr Sci Vitaminol (Tokyo) 47, 147-155.

38. Marmot MG, Elliott P, Shipley MJ, Dyer AR, Ueshima H, Beevers DG, Stamler R, Kesteloot H, Rose G \& Stamler J (1994) Alcohol and blood pressure: the INTERSALT study. BMJ 308, 1263-1267.

39. Grassi GM, Somers VK, Renk WS, Abboud FM \& Mark AL (1989) Effects of alcohol intake on blood pressure and sympathetic nerve activity in normotensive humans: a preliminary report. J Hypertens Suppl 7, S20-S21.

40. Kojima S, Kawano Y, Abe $\mathrm{H}$, Sanai $\mathrm{T}$, Yoshida $\mathrm{K}$, Imanishi M, Ashida T, Kimura G, Yoshimi $\mathrm{H} \&$ Matsuoka $\mathrm{H}$ (1993) Acute effects of alcohol ingestion on blood pressure and erythrocyte sodium concentration. J Hypertens 11, $185-190$

41. Giannattasio C, Mangoni AA, Stella ML, Carugo S, Grassi G \& Mancia G (1994) Acute effects of smoking on radial artery compliance in humans. $J$ Hypertens $\mathbf{1 2}$, 691-696.

42. Terres W, Becker P \& Rosenberg A (1994) Changes in cardiovascular risk profile during the cessation of smoking. Am J Med 97, 242-249.

43. Niskanen L, Laaksonen DE, Nyyssonen K, Punnonen K, Valkonen VP, Fuentes R, Tuomainen TP, Salonen R \& Salonen JT (2004) Inflammation, abdominal obesity, and smoking as predictors of hypertension. Hypertension $\mathbf{4 4}$, 859-865.

44. Li W, Jiang X, Ma H et al. (2003) Awareness, treatment and control of hypertension in patients attending hospital clinics in China. J Hypertens 21, 1191-1197. 